\title{
A novel three-in-one silicone model for basic microsurgery training
}

\author{
Osaid Alser ${ }^{1} \cdot$ Gehad Youssef $^{2} \cdot$ Simon Myers ${ }^{1} \cdot$ Ali M. Ghanem ${ }^{1}$
}

Received: 31 January 2020 / Accepted: 30 March 2020 / Published online: 20 April 2020

(C) The Author(s) 2020

\begin{abstract}
Background Microsurgery simulation is an important aspect of surgical training. Animal models have been widely used in simulation training, but they have some limitations including ethical restrictions, cost and availability. This has led to the use of synthetic models that can reduce reliance on animals in line with the $3 \mathrm{R}$ (refinement, reduction and replacement) principles. The aim of this paper was to evaluate the face validity of Surgitate ${ }^{\mathrm{TM}}$ three-in-one (artery, vein and nerve) silicone model.

Methods Fourteen candidates performed one end-to-end anastomosis on artery, vein and nerve. The face validity of the vessel was assessed via questionnaires detailing their previous microsurgical experience and their feedback of using this model using the Likert scale. Data management and analysis were performed using IBM SPSS software (25.0).

Results Participants tended to value this model in the earlier stages of microsurgical training particularly in the acquisition of basic microsurgical skills. It could be particularly useful in enhancing suturing skills as a replacement or reduction in the use of chicken models. The model has some drawbacks preluding its utilization into more advanced stages of surgical training. Further studies are needed to validate the model using more objective measures.

Conclusion We present a novel synthetic model that can be potentially introduced to early stages of microsurgery training. The model would be ideal to meet the $3 \mathrm{R}$ principles of the use of animal models and as an alternative to the commonly used synthetic models.

Level of evidence: Not ratable.
\end{abstract}

Keywords Microsurgery $\cdot$ Anastomosis $\cdot$ Training $\cdot$ Simulation $\cdot$ Education $\cdot$ Animal replacement

\section{Introduction}

Simulation surgical training helps surgical trainees optimise their performance in the operating theatres while also providing a means for evaluation of their skills [1]. Microsurgery

\section{Ali M. Ghanem \\ a.ghanem@qmul.ac.uk \\ Osaid Alser \\ osaidalserr@hotmail.com \\ Gehad Youssef \\ g.youssef@qmul.ac.uk}

Simon Myers

simon.myers@qmul.ac.uk

1 Academic Plastic Surgery Group, Blizard Institute, Barts and the London School of Medicine and Dentistry, 4 Newark St, London E1 2AT, UK

2 The Animal Replacement Centre of Excellence (The ARC), Centre for Cutaneous Research, Blizard Institute, Barts and the London School of Medicine and Dentistry, London, UK simulation is becoming an essential training method for acquisition and maintenance of microsurgical skills $[2,3]$. While animal models have been extensively used in surgical training, there are some limitations with the use of animal models. There are ethical considerations with the use of living models, and this has resulted in a trend towards development of simulation models that can reduce reliance on animals in line with the $3 \mathrm{R}$ (refinement, reduction and replacement) principles [4-6]. Moreover, although live animal models do confer great face validity, they require a dedicated animal care facility and trained staff. Thirdly, despite the high fidelity, there are still anatomical and physiological differences between human tissue and animal models. Finally, the high cost of surgical training resulted in development and spread of many non-living animal and synthetic models for microsurgery simulation [7]. The main advantage of using synthetic models in microsurgery training is that they can potentially be curated to exhibit with greater fidelity human tissue and to improve specific subtasks such as suturing skills or nerve damage repair. We published a design of a 5-day basic microsurgery simulation training course [8] in which we used synthetic models during the 
first day followed by non-living animal models (chicken) for the rest of the course.

The aim of this paper was to evaluate the face validity of Surgitate ${ }^{\mathrm{TM}}$ three-in-on silicone slab model that can serve as an animal-free alternative to be incorporated into early microsurgical training towards replacing, refining and reducing the use of animal models in microsurgery training.

\section{Materials and methods}

We evaluated the face validity of a three-in-one (artery, vein and nerve) synthetic silicone slab model designed by a simulation company (Surgitate ${ }^{\mathrm{TM}}$ ) - (Fig. 1). One end-to-end anastomosis on artery, vein and nerve was performed using 10-0 sutures following training on chicken thigh models by 14 candidates from our Reconstructive Microsurgery MSc programme, Queen Mary University of London, at the Center of Biotechnology, Naples, Italy. The face validity of the vessel was assessed via questionnaires detailing previous microsurgical experience on human tissue, animal and synthetic models, their current level of surgical training, and their feedback of using this model using the Likert scale to evaluate validity of using the arterial, venous and nerve component of the model and to elicit comparisons with animal models.

Data management and analysis were performed using IBM SPSS Statistics for Windows, Version 25.0 (Armonk, NY: IBM Corp.). In order to assess the value that participants gained from using the slab model in their microsurgical training, we correlated the participant's feedback at the end of the course using Pearson's correlation. A partial (second) order correlation was performed controlling for lead experience in microvascular anastomosis to determine the extent that the Surgitate model was being perceived in the surgical training paradigm. Statistical significance was accepted with $P$ value $<0.05$.

\section{Results}

As shown in Table 1, most participants were males (10/14, $71 \%$ ) and had limited surgical training experience. For example, $57 \%$ of the participants had from less than 5 years of experience in microsurgery and spent less than 10 days in total in microsurgery simulation training sessions. Seventy-two percent of the participants performed a maximum of $10 \mathrm{mi}-$ crovascular procedures, and $62 \%$ performed microsurgical nerve repair independently in real clinical setting. The most commonly used microsurgery simulation training models were chicken $(86 \%)$ and rats (living $(71 \%)$ and non-living $(57 \%))$. Prior training with synthetic models was low $(36 \%)$ reflecting the reluctance of surgical training programmes to incorporate synthetic models with questionable validity.

As Table 2 shows, most participants (93\%) recommended using Surgitate model for basic microsurgery skills acquisition. A similar proportion of the participants felt that the model is an excellent training model to prepare them for performing microvascular and microneural repair on human tissue, and $57 \%$ of the participants felt that the model does not resemble microsurgical training in the real clinical setting. As seen in Table 3, participants who strongly recommended the slab model to be included in basic microsurgical training were significantly likely to report that they agree that the slab model provides good basic training in terms of acquisition and maintenance of microvascular and microneural repair skills as well as preparing them to the actual clinical setting. The correlations between recommending the slab model for microvascular and microneural repair skills acquisition and preparation for actual clinical setting were largely unaffected following the partial order correlation, whereas the perception that the slab model is adequate for maintenance of microsurgery skills was reduced.

In Table 4, compared to chicken models, the participants appreciated Surgitate model mainly for acquisition of

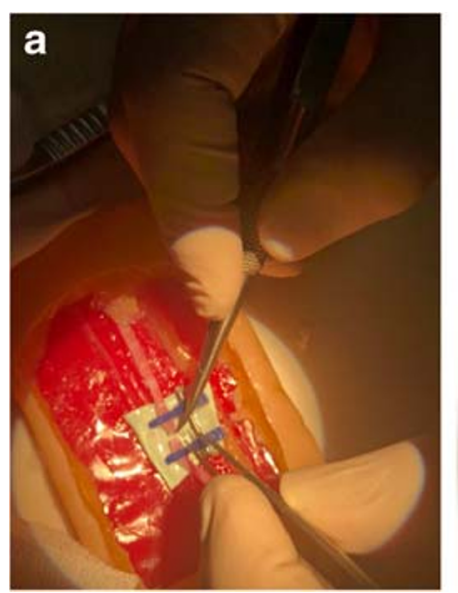

b

Fig. 1 a. Surgitate silicone model allowing microvascular anastomosis on a vessel, b. Illustration of the layers comprising the model (left to right: nerve, artery and vein) 
Table 1 Demographic data and previous microsurgery experience of the participants in the training course

\begin{tabular}{|c|c|c|c|}
\hline & Grouping & Frequency & $\begin{array}{l}\text { Percentage } \\
(N=14)\end{array}$ \\
\hline \multirow[t]{2}{*}{ Gender } & Male & 10 & $71 \%$ \\
\hline & Female & 4 & $29 \%$ \\
\hline \multirow[t]{3}{*}{ Years of surgical training } & $1-4$ & 8 & $57 \%$ \\
\hline & $5-8$ & 4 & $14 \%$ \\
\hline & $>8$ & 2 & $14 \%$ \\
\hline \multirow{4}{*}{$\begin{array}{l}\text { Previous microsurgery simulation } \\
\text { training attended (days) }\end{array}$} & 5 & 6 & $43 \%$ \\
\hline & $6-10$ & 2 & $14 \%$ \\
\hline & $>10$ & 4 & $29 \%$ \\
\hline & N/A & 2 & $14 \%$ \\
\hline \multirow{5}{*}{$\begin{array}{l}\text { Prior experience as the lead } \\
\text { (independent) surgeon in } \\
\text { microvascular (arteries or } \\
\text { veins) anastomosis }\end{array}$} & 0 & 4 & $29 \%$ \\
\hline & $1-10$ & 6 & $43 \%$ \\
\hline & $11-20$ & 1 & $7 \%$ \\
\hline & $21-30$ & 1 & $7 \%$ \\
\hline & $>30$ & 2 & $14 \%$ \\
\hline \multirow{5}{*}{$\begin{array}{l}\text { Prior experience as the lead } \\
\text { (independent) surgeon in } \\
\text { microsurgical nerve repair }\end{array}$} & 0 & 1 & $7 \%$ \\
\hline & $1-10$ & 8 & $57 \%$ \\
\hline & $11-20$ & 2 & $14 \%$ \\
\hline & $21-30$ & 1 & $7 \%$ \\
\hline & $>30$ & 2 & $14 \%$ \\
\hline \multirow[t]{6}{*}{ Previous training models used } & Chicken & 12 & $86 \%$ \\
\hline & Rats (living) & 10 & $71 \%$ \\
\hline & Rats (non-living) & 8 & $57 \%$ \\
\hline & Pigs & 6 & $43 \%$ \\
\hline & Micro-trainer and silicon tubes & 5 & $36 \%$ \\
\hline & None & 1 & $7 \%$ \\
\hline
\end{tabular}

Finally, there was a significant positive correlation (Table 5) between the participants' feedback rating of the degree to which they regarded the slab model as a useful new model for microvascular and microneural anastomosis and the microvascular suturing skills $(79 \%)$ but less likely for training on tissue dissection (36\%) or microvascular anastomosis (43\%). Only $43 \%$ agreed that Surgitate model adequately resembles performing microsurgical procedures on live animal models.

Table 2 Face validity feedback responses to elicit participants' experiences with the Surgitate model compared to microsurgery training in real clinical setting (human tissue)

\begin{tabular}{|c|c|c|c|}
\hline Post-training feedback & $\begin{array}{l}\text { Strongly/moderately } \\
\text { agree }(n, \%)\end{array}$ & Neutral $(n, \%)$ & $\begin{array}{l}\text { Strongly } / \text { moderately } \\
\text { disagree }(n, \%)\end{array}$ \\
\hline $\begin{array}{l}\text { "I recommend basic courses with the course in a slab model } \\
\text { for trainees for microsurgery skill acquisition" }\end{array}$ & $13(93 \%)$ & 0 & $1(7 \%)$ \\
\hline $\begin{array}{l}\text { "This training using course in a slab models is excellent } \\
\text { training as preparation for microvascular and microneural } \\
\text { repair" }\end{array}$ & $11(79 \%)$ & $3(21 \%)$ & 0 \\
\hline $\begin{array}{l}\text { "This training using course in a slab models is excellent training } \\
\text { for maintenance of skills involved in microvascular and } \\
\text { microneural repair" }\end{array}$ & $7(50 \%)$ & $5(36 \%)$ & $2(14 \%)$ \\
\hline $\begin{array}{l}\text { "It is possible to learn all exercises of microvascular repair type } \\
\text { using the new model for basic course" }\end{array}$ & $11(14 \%)$ & $1(7 \%)$ & $2(14 \%)$ \\
\hline $\begin{array}{l}\text { "The course in a slab model would facilitate skills acquisition } \\
\text { prior to actual clinical setting" }\end{array}$ & $13(93 \%)$ & $1(7 \%)$ & 0 \\
\hline $\begin{array}{l}\text { "This training using course in a slab models adequately } \\
\text { resembles operating on human tissue/the clinical setting" }\end{array}$ & $4(29 \%)$ & $2(14 \%)$ & $8(57 \%)$ \\
\hline
\end{tabular}


Table 3 Pearson's correlation between feedbacks

\begin{tabular}{|c|c|c|c|}
\hline Feedback & Feedback & $\begin{array}{l}\text { Pearson's correlation } \\
\text { (zero order) }\end{array}$ & $\begin{array}{l}\text { Pearson's correlation } \\
\left(\text { partial order }{ }^{\mathrm{a}} \text { ) }\right.\end{array}$ \\
\hline \multirow{3}{*}{$\begin{array}{l}\text { "I recommend basic courses with } \\
\text { the course in a slab model for } \\
\text { trainees for microsurgery skill } \\
\text { acquisition" }\end{array}$} & $\begin{array}{l}\text { "The course in a slab model would facilitate } \\
\text { skills acquisition prior to actual clinical } \\
\text { setting" }\end{array}$ & $0.759 * *$ & $0.736^{* *}$ \\
\hline & $\begin{array}{l}\text { "This training using course in a slab models } \\
\text { is excellent training as preparation for } \\
\text { microvascular and microneural repair" }\end{array}$ & $0.756^{* *}$ & $0.793 * *$ \\
\hline & $\begin{array}{l}\text { "This training using course in a slab models } \\
\text { is excellent training for maintenance of } \\
\text { skills involved in microvascular and } \\
\text { microneural repair" }\end{array}$ & $0.295^{*}$ & 0.229 \\
\hline
\end{tabular}

*One-tailed significance $<0.05, * *$ significance $<0.01$, a partial (second) order correlation after controlling for lead experience in microvascular anastomosis and microneural repair

resemblance of the slab model to human tissue and animal models.

\section{Discussion}

Alternative synthetic models have been introduced for microsurgery simulation training trying to comply with the $3 \mathrm{R}$ principles. Therefore, microsurgery simulation training nowadays usually begins teaching surgical trainees using low-fidelity synthetic models and progress and increase in complexity until it reaches a high-fidelity model such as living rat, which is the gold standard [7-10]. These synthetic models include suture practice cards, rubber pads, bubble wrap, latex and vinyl gloves, silicone and polyvinyl alcohol gelatin tubes and many others [5, 10-11]. Atlan et al. [12] believe that although most synthetic models are considered as low-fidelity models, however, they are easy to access, and they shorten learning curve and facilitate basic microsurgical skills acquisition. These basic skills include instrument handling, microscope positioning and suturing $[15,16]$.
Weber et al. [17] and Yen et al. [18] described a similar three-in-one model (PracticeRat) that allows nerve repair and arterial and venous anastomosis artery made of polyethylene tubes assembled in Petri dish. Although it is made of simple materials and it allows the trainee to check their vascular anastomosis patency, its cost is relatively high, and it does not offer realistic dissection of the surrounding tissues including the adventitia and is not a good model for practicing nerve repair.

Our study results demonstrate that Surgitate three-in-one silicone model could be a useful replacement to the use of animal models especially at basic stages of microsurgical simulation training. This model could be particularly useful in enhancing suturing skills as a replacement and a reduction in the use of chicken models. This model can be also suitable for performing microvascular anastomosis in end-to-end and endto-side fashions and end-to-end anastomosis of vessels with size discrepancy and inter-positional graft, similar to the rat model described by Shurey et al [7]. It offers up to 18 different exercises on artery, vein and nerve, boxed in a model.

There were some drawbacks that preluded the utilisation of the slab model into more advanced stages of surgical training, primarily objections to the vein being too-thick walled, poor

Table 4 Face validity feedback responses to elicit participants' experiences with the Surgitate model compared to animal models

\begin{tabular}{llll}
\hline Post-training feedback & $\begin{array}{l}\text { Strongly/moderately } \\
\text { agree }(n, \%)\end{array}$ & Neutral $(n, \%)$ & $\begin{array}{c}\text { Strongly/moderately } \\
\text { disagree }(n, \%)\end{array}$ \\
$\begin{array}{l}\text { "This training using course in a slab models adequately } \\
\text { presents the dissection components of the exercise } \\
\text { completed in non-living chicken model" }\end{array}$ & $5(36 \%)$ & $5(36 \%)$ & $4(29 \%)$ \\
$\begin{array}{l}\text { "This training using course in a slab models adequately } \\
\text { presents the preparation for anastomosis components } \\
\text { of the exercise completed in a non-living chicken model" }\end{array}$ & $6(43 \%)$ & $6(43 \%)$ & $2(14 \%)$ \\
$\begin{array}{l}\text { "This training using course in a slab models adequately } \\
\text { presents the microvascular suturing skills components } \\
\text { of the exercise completed in a non-living chicken model" }\end{array}$ & $11(79 \%)$ & $1(7 \%)$ & $2(14 \%)$ \\
"The training using course in a slab model adequately \\
resembles operating on live animal models"
\end{tabular}


Table 5 Pearson's correlation between feedback responses

\begin{tabular}{|c|c|c|c|}
\hline Feedback & Feedback & $\begin{array}{l}\text { Pearson's correlation } \\
\text { (zero order) }\end{array}$ & $\begin{array}{l}\text { Pearson's correlation } \\
\left(\text { partial order }^{a}\right)\end{array}$ \\
\hline \multirow[t]{5}{*}{$\begin{array}{l}\text { "It is possible to learn all exercises of } \\
\text { microvascular repair type using } \\
\text { the new model for basic course" }\end{array}$} & $\begin{array}{l}\text { "This training using course in a slab models } \\
\text { adequately resembles operating on human } \\
\text { tissue/the clinical setting" }\end{array}$ & $0.488^{*}$ & 0.235 \\
\hline & $\begin{array}{l}\text { "The training using course in a slab model } \\
\text { adequately resembles operating on live } \\
\text { animal models" }\end{array}$ & $0.600 *$ & 0.279 \\
\hline & $\begin{array}{l}\text { "This training using course in a slab models } \\
\text { adequately presents the dissection } \\
\text { components of the exercise completed } \\
\text { in non-living chicken model" }\end{array}$ & $0.463 *$ & 0.461 \\
\hline & $\begin{array}{l}\text { "This training using course in a slab models } \\
\text { adequately presents the preparation for } \\
\text { anastomosis components of the exercise } \\
\text { completed in a non-living chicken model" }\end{array}$ & $0.515^{*}$ & 0.279 \\
\hline & $\begin{array}{l}\text { "This training using course in a slab models } \\
\text { adequately presents the microvascular } \\
\text { suturing skills components of the exercise } \\
\text { completed in a non-living chicken model" }\end{array}$ & $0.746 * *$ & $0.766 * *$ \\
\hline
\end{tabular}

*One-tailed significance $<0.05$, **significance $<0.01$, a partial (second) order correlation after accounting for lead experience in microvascular anastomosis or nerve repair

plasticity of the vessels as compared to animal model or human tissue and poor opposition of the intima. Moreover, most participants showed that there was a disparity between their surgical experience and the value of the use of this model for simulation training. The participants have also expressed that this model does not replicate true clinical scenarios such as a pulsatile vessel, easy-to-dissect adventitia and mimicking radiated or atherosclerotic vessels. These drawbacks are not insurmountable, and we have informed the manufacturer of these comments, and hopefully future developments of this slab model will take these design pitfalls into considerations to design a more clinically advanced microvascular training model. The cost of the slab model (around \$150) exceeds that of the chicken and that is another limitation; however, we envision that the utility of this model is in its "boxable" nature where it could serve as a commercial proof of concept for demonstration of microsurgical techniques particularly suturing tools. Moreover, the model does offer potential advantages such as ethical replacement of animal models, no need for preservation and refrigeration which provides a permanent record for evaluation of performance. Thus, further studies are needed to evaluate its cost-effectiveness.

The study has some limitations, and these include small sample size and therefore lack of enough generalizability, and no pre-training model evaluation was sought from the participants to compare it with this post-training evaluation. However, the present study has some important strengths; for example, we provided a thorough evaluation of the model in terms of being useful for microsurgical skills acquisition and maintenance and preparation for actual clinical setting. We have also provided a comparison between this model and commonly used animal models in microsurgical training.

Future work should consider further model validation using hand motion analysis (HMA) and global rating scores (GRS) on standardised exercises as suggested by Ramachandran et al. [19]. For end-product assessment, the Anastomosis Lapse Index (ALI) score [3] can be used theoretically, but as the silicone walls would not fold, a similar analysis of errors to validate end-product assessment will be necessary.

\section{Conclusion}

We present a novel synthetic model that can be potentially introduced to early stages of microsurgery training that would be ideal to meet the $3 \mathrm{R}$ principles of the use of animals. We propose that this three-in-one synthetic silicone model for microvascular training is a useful beginner-level alternative to the commonly used synthetic and animal models.

Acknowledgements We thank Dr. Ozge Akbulut from Surgitate company (TOSB 1. CADDE 31. SOKAK NO:1 ÇAYIROVA/KOCAELİ, Turkey) for providing the model and the figures.

Authors' contribution All authors contributed to the study conception and design. Material preparation, data collection and analysis were performed by OA, GY, SM and AMG. The first draft of the manuscript was written by $\mathrm{OA}$, and all authors commented on previous versions of the manuscript. All authors read and approved the final manuscript. 
Data Availability Data can be provided for reviewers upon request.

\section{Compliance with ethical standards}

Conflict of interest Osaid Alser, Gehad Youssef, Simon Myers and Ali M. Ghanem declare that they have no conflict of interest. The manufacturer of this model had no role in study design, data collection, data analysis, data interpretation, or manuscript preparation. The views expressed in this manuscript are those of the authors only.

Ethical approval Ethical approval was not needed as the study did not involve patients or animals.

Consent to participate Informed consent was obtained from participants and they agreed to fill in the questionnaire.

Consent for publication Participants agreed to have their data published in journal articles.

Open Access This article is licensed under a Creative Commons Attribution 4.0 International License, which permits use, sharing, adaptation, distribution and reproduction in any medium or format, as long as you give appropriate credit to the original author(s) and the source, provide a link to the Creative Commons licence, and indicate if changes were made. The images or other third party material in this article are included in the article's Creative Commons licence, unless indicated otherwise in a credit line to the material. If material is not included in the article's Creative Commons licence and your intended use is not permitted by statutory regulation or exceeds the permitted use, you will need to obtain permission directly from the copyright holder. To view a copy of this licence, visit http://creativecommons.org/licenses/by/4.0/.

\section{References}

1. Nimmons GL, Chang KE, Funk GF, Shonka DC, Pagedar NA (2012) Validation of a task-specific scoring system for a microvascular surgery simulation model. Laryngoscope. 122(10):21642168

2. Rodriguez JR, Yanez R, Cifuentes I, Varas J, Dagnino B (2016) Microsurgery Workout: A Novel Simulation Training Curriculum Based on Nonliving Models. Plast Reconstr Surg 138(4):739e$747 \mathrm{e}$

3. Ghanem AM, Al Omran Y, Shatta B, Kim E, Myers S (2016) Anastomosis lapse index (ALI): a validated end product assessment tool for simulation microsurgery training. J Reconstr Microsurg 32(3):233-241
4. Russell WMS, Burch RL (1959) The sources, incidence, and removal of inhumanity. In: The principles of humane experimental technique. London: Methuen. https://caat.jhsph.edu/principles/ chap4d (Accessed 15 March 2020)

5. Fanua SP, Kim J, Shaw Wilgis EF (2001) Alternative model for teaching microsurgery. Microsurgery. 21(8):379-382

6. Lannon DA, Atkins JA, Butler PE (2001) Non-vital, prosthetic, and virtual reality models of microsurgical training. Microsurgery. 21(8):389-393

7. Shurey S, Akelina Y, Legagneux J, Malzone G, Jiga L, Ghanem AM (2014) The rat model in microsurgery education: classical exercises and new horizons. Arch Plast Surg 41(3):201-208

8. Singh M, Ziolkowski N, Ramachandran S, Myers SR, Ghanem AM (2014) Development of a five-day basic microsurgery simulation training course: a cost analysis. Arch Plast Surg 41(3):213-217

9. Atlan M, Lellouch AG, Legagneux J, Chaouat M, Masquelet A-C, Letourneur D (2018) A new synthetic model for microvascular anastomosis training? A randomized comparative study between silicone and polyvinyl alcohol gelatin tubes. J Surg Educ 75(1): $182-187$

10. Prunieres GJ-C, Taleb C, Hendriks S et al (2014) Use of the Konnyaku Shirataki noodle as a low fidelity simulation training model for microvascular surgery in the operating theatre. Chir Main 33(2):106-111

11. Peled IJ, Kaplan HY, Wexler MR (1983) Microsilicone anastomoses. Ann Plast Surg 10(4):331-332

12. Mutoh T, Ishikawa T, Ono H, Yasui N (2010) A new polyvinyl alcohol hydrogel vascular model (KEZLEX) for microvascular anastomosis training. Surg Neurol Int 1:74

13. Sener S, Menovsky T, Maas AIR (2013) Use of bubble wrap for microsurgical training. J Reconstr Microsurg 29(09):635-636

14. Awwad AM (1984) A training card for microsurgery. Microsurgery. 5(3): 160

15. Lee S, Coppersmith WJ (1983) A microvascular surgical practice disc for beginners. Microsurgery. 4(1):67-69

16. Evgeniou E, Walker H, Gujral S (2018) The role of simulation in microsurgical training. J Surg Educ 75(1):171-181

17. Weber D, Moser N, Rosslein R (1997) A synthetic model for microsurgical training: a surgical contribution to reduce the number of animal experiments. Eur J Pediatr Surg 7(4):204-206

18. Yen DM, Arroyo R, Berezniak R, Partington MT (1995) New model for microsurgical training and skills maintenance. Microsurgery. 16(11):760-762

19. Ramachandran S, Ghanem AM, Myers SR (2013) Assessment of microsurgery competency-where are we now? Microsurgery. 33(5): 406-415

Publisher's note Springer Nature remains neutral with regard to jurisdictional claims in published maps and institutional affiliations. 